\title{
Portfolio Balance Approach to Asymmetries, Structural Breaks and Financial Crisis: Testing a Model for Nigeria
}

\section{Oluwasegun B. Adekoya ${ }^{1}$}

This study tests the Portfolio Balance Theory (PBT) for Nigeria for the period starting from September, 1997 to September, 2018. It extends the hypothesized linear inverse relationship between exchange rate and stock price to include asymmetries and structural breaks. It further examines the impact of the 2008 global financial crisis on the PBT to determine its stability after the crisis. The full sample results show that the PBT holds for Nigeria and asymmetries and structural breaks matter in the nexus between stock price and exchange rate. However, the impact of stock price on exchange rate diminished in the long-run with the advent of the 2008 global financial crisis, thus eroding the relative consistency of the PBT after the crisis. The sensitivity of the Nigerian exchange rate to stock price changes calls for the strengthening of the stock market performance through relevant policies including the enhancement of portfolio diversification and risk-hedging assets. The role of asymmetries should not also be jettisoned in predicting exchange rate with stock prices to obtain accurate forecast results.

Keywords: Asymmetries, exchange rate, global financial crisis, portfolio balance theory, stock price, structural breaks.

JEL Classification: F31, G11

DOI: $10.33429 /$ Cjas.11120.4/5

\section{Introduction}

The rising evidence of globalization and financial market inter-relationship, reduction in cases of autarky (which erodes capital inflow restrictions) and the adoption of the flexible or floating exchange rate regimes in many countries have led to strong and strategic interdependence between the stock and the foreign financial markets. Aydemir and Demirhan (2009) note that this integration has been feasible since the 1980s. Since then, researchers have been motivated to empirically unravel the relationship between the stock market and the foreign financial market. Another reason for determining the interdependence between the two markets is because of their role in portfolio management and domestic policy formulation (Dahir et al., 2017, Leung et al., 2017).

\footnotetext{
${ }^{1}$ Department of Economics, Federal University of Agriculture, Abeokuta, Nigeria. Email: adekoyaob@gmail.com, Mobile: +2348168889097

The views expressed in this paper are solely those of the author and do not necessarily represent those of the Central Bank of Nigeria.
} 
In respect of these inter-linkages, two schools of thought have emerged. The foremost argues that the behaviour of financial assets is largely driven by both financial and economic risks. This thought is mainly rooted in the two common classes of financial asset theories: Capital Asset Theory Models (CAPM) (see Sharpe, 1964; Lintner, 1965, inter-alia) and Arbitrage Pricing Theory (APT) proposed by Ross (1976). While the former theory supports a single risk factor affecting stock prices, the other indicates that a single variable is not sufficient in explaining the diversities or overall behaviour of financial assets. Hence, it inculcates other risk factors that appear to be closely linked with the stock market behaviour, such as interest rate, inflation and output.

In the spirit that it is financial assets that are affected by economic and financial factors, exchange rate has enjoyed significant attention in the literature to cause stock market behaviour $^{2}$, as theoretically underpinned by the early study of Dornbusch and Fischer (1980). However, subsequent studies have shown that the relationship varies as it can either be positive or negative depending on the status of the firm as a net-exporter or net-importer. For a country with export-based firms, domestic currency depreciation enhances net exports and then raises stock prices, thus making the impact negative. The converse holds for an economy with import-oriented firms. This theory has been confirmed by a list of studies including Mitra (2017), Pan et al. (2007) and Aggarwal (1981).

On the other hand, the second school interestingly advocates a negative relationship between exchange rate and stock prices, with causality running from the latter to the former. Established via the Portfolio Balance Theory (PBT) independently introduced by Branson (1983) and Frankel (1983), the stock market behaviour may also influence exchange rate via the transmission mechanism of demand for money (Gavin, 1989). Hence, flow-oriented ${ }^{3}$ and stock-oriented models are the two theoretical foundations upon which the PBT takes effect.

This study analyses the PBT on the basis of the stock-oriented adjustments. As explained by Branson (1983) and Frankel (1983), the capital account is the link through which exchange rate is influenced by stock market behaviour. For instance, reduction in stock prices causes

\footnotetext{
${ }^{2}$ Dahir et al. (2017) provides comprehensive review of empirical studies that consider exchange rate as the determinant of the stock market performance.

${ }^{3}$ See the work of Dornbusch and Fisher (1980) for comprehensive explanation of the flow-oriented model.
} 
a huge fall in capital inflows, as it severely penalizes investments from foreign sources. This makes demand for domestic currency falls, thereby leading to currency depreciation. The converse is also true. An increase in domestic stock prices raises its returns, thus causing higher demand for domestic currency. A plethora of studies that has assessed the validity of the PBT include Zivkov et al. (2016), Khan and Abbas (2015), Kutty (2010), Moore and Wang (2014), Chkili and Nguyen (2014). Study of this nature is important for Nigeria at a time like this when the exchange rate is exhibiting high volatility, suggesting the need to examine its determinants. Moreover, the strong integration between the foreign and domestic financial markets makes this study to turn to stock prices as a probable determinant of exchange rate, and is assessed through the PBT, while accounting for certain factors capable of altering the nexus. Certainly, factors including inflation, interest rates and financial crises can induce risks in a market, and can lead investors to consider other markets. This leads to the possible integration.

A major contribution of this paper therefore is to establish or annul the validity of the PBT in Nigeria while considering shocks, structural breaks and the global financial crisis of 2008. This study is of great relevance as it is one of the foremost to consider all these real-life circumstances (shocks, structural breaks and financial crisis) in a single study. Meanwhile, a better understanding of the interdependencies among financial markets is one of the most important tasks for investors and policy makers. The occurrence of these factors however has the tendency of altering the interdependencies. Indeed, a good number of studies have been done on exchange rate-stock market in Nigeria (see Zubair, 2013; Aliyu, 2009; Adjasi, et al., 2011; Osamwonyi and Evbayiro-Osagie, 2012; Okpara and Odionye, 2012; Adaramola, 2012, inter-alia), but this study assesses the PBT in different innovative dimensions. First, studies that have tested the PBT with reference to the asymmetric behaviour of the stock market globally are limited. The above cited studies on Nigeria have largely used the VAR methodology without the consideration of asymmetries.

Second, this study improves on the identified gaps in the existing literature by considering structural breaks which are common to series with high frequency, and for which neglect could bias the model estimates (see Fasanya et al., 2018; Salisu and Fasanya, 2013). Lastly, the dataset is further partitioned into two to reflect the periods before and after the global financial crisis of 2008. The aim is to examine the impact of the 2008 global financial crisis 
on the exchange rate-stock market nexus.

The remaining sections are structured thus: Section 2 provides the literature review, Section 3 describes the data methodology, Section 4 presents and discusses the empirical findings, and Section 5 concludes the study and provides relevant policy recommendations.

\section{Literature Review}

\subsection{Theoretical Literature}

Majority of studies carried out on stock market and exchange rate relationship have focused on the causality running from the latter to the former. Very few studies have also attempted to unravel the possibility of stock prices affecting exchange rate as explained by the Portfolio Balance Theory (PBT). The first set of theories that underpin the causal relationship between exchange rate and stock market indices are the Capital Asset Pricing Model (CAPM) and Arbitrage Pricing Theory (APT). The two theories suggest that financial and economic risks, including exchange rate, are the principal drivers of stock market performance, although the APT gives more room for multiple risk factors unlike the CAPM (see Ross, 1976). Following the early work of Dornbusch and Fischer (1980), a plethora of studies has been conducted to evaluate the exchange rate-stock market nexus using these theories with mixed findings following (see, for instance, Aggarwal, 1981; Pan et al., 2007; Mitra, 2017; Dahir et al., 2017).

Another common theoretical back up for the interaction between exchange rate and the stock market indices is the Portfolio Balance Theory (PBT) due to Branson (1983) and Frankel (1983). In this case, stock price is the predictor of exchange rate, and this line of empirical consideration has been also attention in the past few years (see Aydemir and Demirhan, 2009; Diamandis and Drakos, 2011; Chkili and Nguyen, 2014; Salisu and Ndako, 2017).

For Nigeria, empirical assessment of the PBT is scarce. Studies that have considered the relationship between the two factors (see, for instance, Zubair, 2013; Aliyu, 2009; Adjasi, et al., 2011; Osamwonyi and Evbayiro-Osagie, 2012; Okpara and Odionye, 2012; Adaramola, 2012, Lawal and Ijirshar, 2015; Omokehinde et al., 2017; Alimi and Adediran, 2018) do not either consider asymmetries and structural breaks which are golden features of the both stock and foreign exchange markets, or do not assess the relationship based on PBT. These existing works also need to be updated because the 2008 financial turmoil has been claimed by many 
authors to cause significant alterations to the relationship between many economic variables. Reference is given to Effiong (2016) whose work is based on the nexus between exchange rate and stock prices in Nigeria in a nonlinear version. However, the work is not based on the nonlinear ARDL methodology, and structural breaks were not considered.

\subsection{Empirical Literature}

That the foreign exchange and stock markets operate at high frequency is not a fact that needs re-establishment. Significant fluctuations often herald the two markets at every little time interval due to demand and supply of stocks and currencies (especially during floating exchange rate regime). This explains the reason for the high volatility and structural shocks mostly experienced by the markets. Hence, empirical studies in other regards have pointed out that annulling asymmetries and structural breaks when dealing with high frequency series, when in actual fact they exist, can lead to bias estimates (see Salisu and Fasanya, 2013; Fasanya et al., 2018).

With respect to the exchange rate-stock price relationship, with causality running from the former to the latter, the original theoretical construct linking these series which is the PBT indicates a symmetric relationship, and this symmetric notion has guided many researchers in their construction of exchange rate-stock price models (see Lin, 2012; Diamandis and Drakos, 2011; Sui and Sun, 2015, inter alia). For instance, Diamandis and Drakos (2011) reveal that the foreign exchange and stock markets have positive relationship in the four countries considered, and that the channel for the links is the US stocks. On the other hand, Sui and Sun (2015) observe from their analysis that in the short-run, spillover is significantly found to run from exchange rates to stock returns, and not the other way round. However, certain studies have taken a diversion from the linearity assumption by providing empirical assessment of the response of exchange rate to stock price asymmetries (see Walid et al., 2011; Salisu and Ndako, 2017). The theoretical explanation was first offered by Dieci and Westerhoff (2013).With strong evidence, the study brilliantly argues that the prediction of exchange rate with asymmetric stock price will provide authentic and more robust information on how to properly hedge stock and currency risks for effective portfolio diversification. The asymmetric tendency in the PBT assessment for the OECD countries is also supported by Salisu and Ndako (2017). They not only validate the PBT for the Euro and non-Euro areas of the OECD, but further establish the effect of asymmetries in both long-run and short-run. 
In addition, Walid et al. (2011) make a case for four emerging economies by employing the Markov-Switching EGARCH model to reveal that volatility in stock prices responds to foreign exchange market activities in an asymmetric manner.

Generally, financial crisis of any sort should never be disregarded in empirical works involving any financial market. Any financial crisis will, often times, start from the financial market. As pointed out by numerous studies, including Salisu and Ndako (2017), Diamandis and Drakos (2011) and Dahir et al. (2017), financial markets experience higher volatilities during crisis periods. They further argue that the foreign exchange market can be the receiving ground of the financial crisis that heralds any financial market. These studies have proved this fact using various crises in different country ${ }^{4}$.

We therefore lean on existing evidence to account for asymmetries and structural breaks in our study, as well as consider the exchange rate-stock price behaviour before and after the global financial crisis of 2008.

\section{Data and Methodology}

\subsection{Data and Sources}

The data employed in this study are the stock market index and official exchange rate of Nigeria on monthly frequency. The scope of the data is from September, 1997 to September, 2018, making a total of 253 observations. The aggregate dataset is partitioned into two covering the periods before and after the global financial crisis of 2008. The aim is to analyze the possible alteration of the exchange rate-stock price relationship induced by the crisis. Based on historical evidence for Nigeria, the effect of the 2008 global financial crisis began to be significantly felt in the early period of the same year. ${ }^{5}$ Therefore, the pre-crisis period analyzed in this study starts from September, 1997 to December, 2007, while January 2998 to

\footnotetext{
${ }^{4}$ Various crises whose impact have been assessed on the exchange rate-stock price relationship include 1994/1995 Mexican crisis, 1997 Asian crisis, 2008 global financial crisis and 2010 European debt crisis (see Salisu and Ndako, 2017).

5 Although a few studies believe that the 2008 global financial crisis began in Nigeria earlier than 2008 (see Aliyu, 2009, for instance), it has been more widely believed that its impact on the financial markets strictly began at that period (see Abraham, 2016 Benjamin and Fatile, 2019; Zubair, 2013).
} 
September, 2018 covers for the crisis and post-crisis period ${ }^{6}$. The datasets are sourced from Global Economic Monitor ${ }^{7}$, and are all expressed in natural logarithm to measure elasticity.

\subsection{Theoretical Framework}

The theoretical foundation of this study is the Portfolio Balance Theory (PBT) based on the stock-oriented adjustments. Generally, the PBT lies in its inability to capture risk premium in the rate of returns of domestic assets in order that foreign portfolio investors could demand for domestic assets. This is principally due to the assumption of no perfect substitution of domestic and foreign assets in the Portfolio Balance approach to the determination of interest rate. The theory emphasizes that change in stock prices relate to exchange rate movements via the capital account. It predicts an inverse relationship between stock prices and exchange rate where decreases in stock prices reduces the motivation for the demand for the stocks as both domestic and foreign investors tend to be attracted to other stocks with higher returns. At the same time, capital inflows reduce while capital outflows rise, and these two resulting outcomes cumulatively reduce the demand for domestic currency in favour of foreign currency, thus causing the former to depreciate (see Dahir et al., 2017 and Diamandis and Drakos, 2011). On the other hand, increases in stock prices attract investors which increases (decreases) demand for domestic and foreign currencies. The result is the appreciation of the domestic currency. In general, the PBT hypothesizes, at least, a short-run inverse relationship between stock price and exchange rate.

\subsection{Model Specification}

From the foregoing, the PBT assumes the following linear equation for the stock price- exchange rate nexus:

$$
r_{t}=\beta+\delta p_{t}+\varepsilon_{t} ; \quad \varepsilon \sim N\left(0, \sigma^{2}\right)
$$

where $r$ is the exchange rate, $\mathrm{p}$ is stock price. Negative relationship is assumed to exist between stock price and exchange rate. As previously noted, empirical studies have revealed that exchange rate can respond to asymmetries in stock prices, implying that the effect of

\footnotetext{
${ }^{6}$ In order not to leave out any observations from the full sample so that substantial empirical information is not lost, we include the observations for both the crisis- and post-crisis periods in a single analysis to represent the post-crisis period. By so doing, we have three rounds of estimation which are: full sample, pre-crisis period and post-crisis period.

7 The website of the datasets is given as: www.databank. worldbank.org/data/reports.aspx ?source=glob al-economic-monitor-\%28gem\%29.
} 
positive stock price shocks could be significantly different from the effect of negative stock price shocks. Therefore, to capture asymmetries in stock price, equation (1) is re-specified thus:

$$
r_{t}=\beta+\delta_{1} p_{t}^{+}+\delta_{2} p_{t}^{-}+\varepsilon_{t}
$$

where $p^{+}$and $p^{-}$are respectively positive and negative stock price changes.

As noted earlier, the preferred choice of technique in this study is the non-linear version of the ARDL model proposed by Shin et al. (2014). This is to determine how exchange rate responds to asymmetries in stock price in both short-run and long-run. To account for possible structural breaks, the non-linear ARDL (NARDL) model is modified to capture the notable significant shifts in the variables.

However, for the sake of robustness, this study rather takes its root from the symmetric model (linear ARDL) and proceeds to the asymmetric model. Under each category of symmetry and asymmetry, the model is estimated with and without breaks. Hence, estimations start by constructing the symmetric ARDL without breaks.

$$
\Delta r_{t}=\alpha_{0}+\sum_{i=1}^{p} \beta_{1 i} \Delta r_{t-i}+\sum_{i=0}^{q} \beta_{2 i} \Delta p_{t-i}+\alpha_{1} r_{t-1}+\alpha_{2} p_{t-1}+\varepsilon_{t}
$$

where $r_{t}$ is exchange rate, and $p_{t} i$ s stock price; both series are in natural logarithm. $\varepsilon_{t}$ is the error term, the long-run coefficients of the intercept and slope respectively are- $\frac{\alpha_{0}}{\alpha_{1}}$ and $-\frac{\alpha_{2}}{\alpha_{1}}$, while the short-run coefficients are $\beta_{1 i}$ and $\beta_{2 i} . p$ and $q$ are the optimal lags on the firstdifferenced variables selected by Schwarz Information Criterion (SIC).

Next, the linear ARDL model is modified to capture endogenous structural breaks. The structural breaks are determined with the Bai-Perron test (see Bai and Perron, 2003). This test helps to identify multiple structural break dates up to five. The newly modified symmetric ARDL with structural breaks is thus given as:

$$
\Delta r_{t}=\alpha_{0}+\sum_{i=1}^{p} \beta_{1 i} \Delta r_{t-i}+\sum_{i=0}^{q} \beta_{2 i} \Delta p_{t-i}+\alpha_{1} r_{t-1}+\alpha_{2} p_{t-1}+\sum_{r=1}^{s} \gamma_{r} B_{r t}+\varepsilon_{t}
$$

As depicted above, the inclusion of $\sum_{r=1}^{s} \gamma_{r} B_{r t}$ in equation (4) captures the breaks, where $B_{r t}$ is a dummy variable for each of the breaks denoted as $B_{r t}=1$ fort $>T_{D}$, otherwise $B_{r t}=0$. The time period is represented by $t ; T_{D}$ indicates the structural break dates where $r=1,2$, $3, \ldots, k$ and $\gamma_{r}$ is the coefficient of the break dummy. Previous identification goes for all other 
parameters.

In examining the role of asymmetries in the model, the non-linear representation of the symmetric ARDL is done. This is in line with the approach of Shin et al. (2014). In this case, the partial sum decomposition of stock prices into positive and negative changes is carried out. The idea of this decomposition is that the response of exchange rate to positive stock price change may be significantly different to negative stock price change. So, before specifying the main Non-linear ARDL (NARDL) model, the formula for the decomposition of stock price into positive $\left(\Delta p_{t}^{+}\right)$and negative $\left(\Delta p_{t}^{-}\right)$partial sums are given below:

$$
\begin{aligned}
& p_{t}{ }^{+}=\sum_{j=1}^{t} \Delta p_{j}{ }^{+}=\sum_{j=1}^{t} \max \left(\Delta p_{j}, 0\right) \\
& p_{t}{ }^{-}=\sum_{j=1}^{t} \Delta p_{j}{ }^{-}=\sum_{j=1}^{t} \min \left(\Delta p_{j}, 0\right)
\end{aligned}
$$

Given the above definitions in equations (5) and (6), asymmetries are accounted for in the symmetric ARDL to produce the non-linear (asymmetric) ARDL model thus:

$$
\Delta r_{t}=\alpha_{0}+\sum_{i=1}^{p} \beta_{1 i} \Delta r_{t-i}+\sum_{i=0}^{q}\left(\beta_{2 i}{ }^{+} \Delta p^{+}{ }_{t-i}+\beta_{2 i}{ }^{-} \Delta p^{-}{ }_{t-i}\right)+\alpha_{1} r_{t-1}+\alpha_{2}{ }^{+} p^{+}{ }_{t-1}+\alpha_{2}{ }^{-} p^{-}{ }_{t-1}+\varepsilon_{t}
$$

The underlying long run parameters are defined as $\varphi^{+}=-\frac{\alpha_{2}{ }^{+}}{\alpha_{1}}$ and $\varphi^{-}=-\frac{\alpha_{2}-}{\alpha_{1}}$, while the short-run adjustments to positive and negative stock price changes are respectively captured by $\beta_{2 i}{ }^{+}$and $\beta_{2 i}{ }^{-}$.

As is the case with the symmetric ARDL model, the NARDL model in equation (7) is further modified to accommodate structural breaks.

$$
\begin{gathered}
\Delta r_{t}=\alpha_{0}+\sum_{i=1}^{p} \beta_{1 i} \Delta r_{t-i}+\sum_{i=0}^{q}\left(\beta_{2 i}{ }^{+} \Delta p^{+}{ }_{t-i}+\beta_{2 i}{ }^{-} \Delta p^{-}{ }_{t-i}\right)+\alpha_{1} r_{t-1}+ \\
\alpha_{2}{ }^{+} p^{+}{ }_{t-1}+\alpha_{2}{ }^{-} p^{-}{ }_{t-1}+\sum_{r=1}^{s} \gamma_{r} B_{r t}+\varepsilon_{t}
\end{gathered}
$$

The parameters are as earlier defined.

\subsection{Estimation Procedure}

The estimation follows a three-step procedure starting with the preliminary analysis which comprises their descriptive properties, trends and stationarity behaviour. The stationarity test does not only guide in the determination of the stability of the series, but much more 
importantly, it informs on the appropriate estimation technique to employ. It also induces the need to further determine the cointegrating nature of the series. For the sake of robustness, two kinds of unit root tests are carried out, with the first not considering structural breaks. Under this category, Dickey-Fuller GLS (DFGLS) and Phillips-Perron (PP) tests are used. Their preference over the popular Augmented Dickey-Fuller (ADF) unit root test lies in their ability to produce more reliable results. While the DFGLS is important in detrending series that are close to the non-stationary region so that the deterministic parameters are efficiently estimated, the PP test is robust to general forms of serial correlation and heteroskedasticity in the residuals. The second class of unit root considered in this study accounts for possible one-time structural breaks along the time-path of the series. Here, the Perron-Vogelsang unit root test (otherwise referred to as the ADF with structural breaks unit root test) is employed. It is a more powerful test of stationarity as others could fail to reject the null hypothesis of no stationarity in the presence of structural breaks (see Fasanya et al., 2018).

The second step involves the generation of results of the main empirical models specified above. Turning to the regression analysis proper, four models are estimated in this study: symmetric ARDL without breaks, symmetric ARDL with breaks, NARDL without breaks and NARDL with breaks. The regression results are generally partitioned into two: the full sample and the sub-samples (pre- and post-global financial crisis). The four models are carried out for the full sample. In other words, symmetric relationship between stock price and exchange rate is first estimated for the full sample. Then, the asymmetric model is evaluated and the positive and negative stock price changes are subjected to Wald test under the null hypothesis that both stock price changes have equivalent effect on exchange rate. The rejection of the null hypothesis implies that asymmetries are necessary to be accounted for. In both cases (symmetric and asymmetric scenarios), structural breaks are accounted for, and their significance are determined via the Joint Significance test. The second fold of the analysis specifically unravels the response of exchange rate to stock price before and after the global financial crisis of 2008 in order to determine if the assertion of the PBT still holds. To achieve this, the full sample is divided into two sub-samples, covering the periods before and after the crisis. Here, the objective is to determine the likely impact of the crisis rather than the consideration of structural breaks. Hence, only the symmetric and asymmetric models are estimated for the sub-samples without giving regards to structural breaks. The asymmetric 
coefficients are also subjected to Wald test as in the case of the full sample. The relevant diagnostic tests are conducted lastly to examine the stability and reliability of the results.

\section{Results and Discussion}

\subsection{Pre-estimation Results}

Conventionally, the statistical properties of the series are first given attention. These are assessed for both aggregate and sub-sampled data for a better capture and comparison.

Table 1: Statistical Properties of Series

\begin{tabular}{llllllll}
\hline Period & Mean & Max. & Min. & $\begin{array}{l}\text { Std. } \\
\text { Dev. }\end{array}$ & Skewness & Kurtosis Obs. \\
\hline Full Sample & 120.4070 & 379.7230 & 34.1040 & 69.2270 & 1.4740 & 5.2910 & 253 \\
Pre-Crisis & 115.8760 & 317.7280 & 34.1040 & 70.8180 & 0.8840 & 2.9840 & 124 \\
Post-Crisis & 124.7630 & 379.7230 & 55.0030 & 67.650 & 2.1590 & 7.6720 & 129 \\
& & \multicolumn{7}{c}{ Exchange Rate } \\
Full Sample & 153.6820 & 362.3940 & 21.8900 & 74.6240 & 1.3080 & 5.0740 & 253 \\
Pre-Crisis & 108.3920 & 142.2370 & 21.8900 & 35.7210 & -1.7230 & 4.6080 & 124 \\
Post-Crisis & 197.2180 & 362.3940 & 116.8080 & 76.4200 & 1.2470 & 3.0160 & 129 \\
\hline
\end{tabular}

Table 1 reveals that both the stock price and exchange rate observe higher average values in the post-crisis period even though stock price significantly fell during the crisis as observed in the graphical illustration provided in Figure 1. However, with significant difference between the maximum and minimum values of the stock prices, and further justified by the high standard deviation value, the stock prices were more volatile before the advent of the crisis. This is unlike exchange rate that seems to be more volatile in the post-crisis period.

Next, the trends in the full sampled series are considered in Figure 1. While exchange rate appears to enjoy a smooth, but relatively increasing trend for most of the periods, stock prices are highly volatile. More importantly, the effect of the 2008 global financial crisis is visibly seen in the stock market index as there is a sharp upward spike in January, 2008, and then continuous drastic fall afterwards until late 2008. This further lends credence to the consideration of January, 2008 as the beginning of the financial turmoil in Nigeria. This stand is also supported by notable studies that suggest that the financial crisis took effect in the very early period of 2008 in Nigeria (see Abraham, 2016; Benjamin and Fatile, 2019; Zubair, 2013). Continuing with the graphical analysis, it is without any gainsaying that a strong negative correlation holds between stock price and exchange rate in the pre-crisis period. This appears to align with the nature of interaction between the variables by the PBT. 
Portfolio Balance Approach to Asymmetries, Structural Breaks and Financial Crisis: Testing a Model for Nigeria

Adekoya

The pattern of correlation appears to be disorganized since January, 2008 as no clear pattern of relationship is noticeable for the first eight years after the crisis. The negative relationship is not found to be restored until after 2016. Although correlation does not strictly indicate causation, but these trends further strengthen the need to find out if the PBT originally holds for Nigeria, as well as if the global financial crisis causes any significant alteration to the likely relationship between stock price and exchange rate.

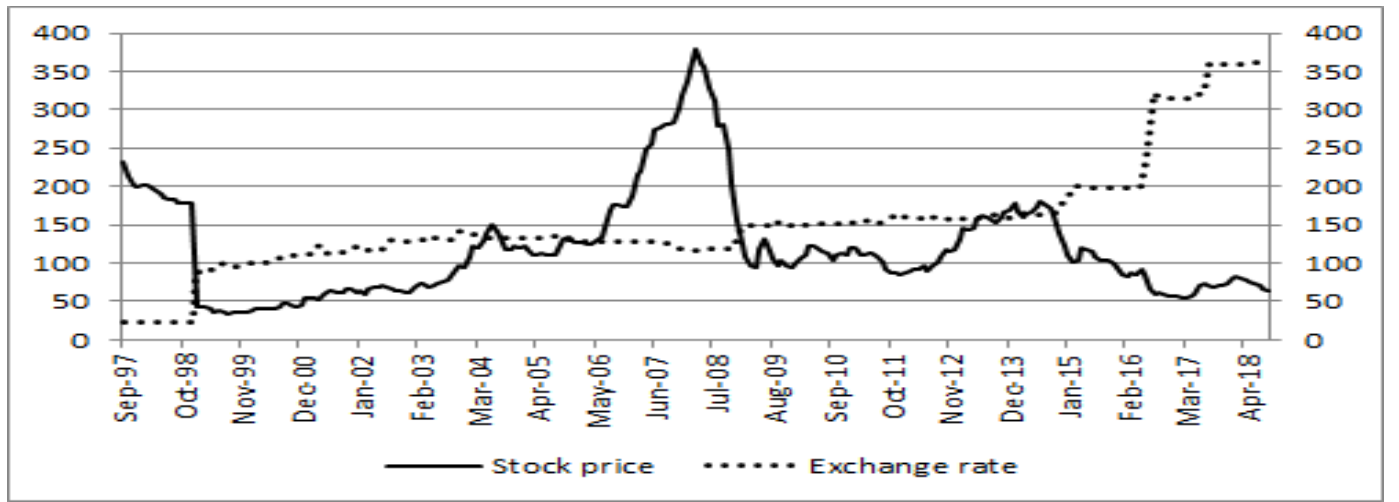

Figure 1: Trends in stock prices and exchange rate in Nigeria

Table 2a: Test of Stationarity Results without Structural Breaks

\begin{tabular}{|c|c|c|c|c|c|c|}
\hline \multirow[t]{2}{*}{ Period } & \multicolumn{3}{|l|}{ DFGLS } & \multicolumn{3}{|c|}{ Phillips-Perron } \\
\hline & Level & First Diff. & $\mathrm{I}(\mathrm{d})$ & Level & First Diff. & $\mathrm{I}(\mathrm{d})$ \\
\hline \multicolumn{7}{|c|}{ Stock Prices } \\
\hline Full Sample & $-1.571^{b}$ & $-5.756^{b, *}$ & $\mathrm{I}(1)$ & $-2.317^{b}$ & $-13.678^{b, *}$ & $\mathrm{I}(1)$ \\
\hline Pre-Crisis & $-0.751^{b}$ & $-10.917^{b, *}$ & $\mathrm{I}(1)$ & $-2.249^{b}$ & $-10.908^{b, *}$ & $\mathrm{I}(1)$ \\
\hline Post-Crisis & $-1.928^{b}$ & $-5.652^{b, *}$ & $\mathrm{I}(1)$ & $-2.290^{b}$ & $-6.543^{b, *}$ & $\mathrm{I}(1)$ \\
\hline \multicolumn{7}{|c|}{ Exchange Rate } \\
\hline Full Sample & $-12310^{b}$ & $-15.535^{b, *}$ & $\mathrm{I}(1)$ & - & - & $\mathrm{I}(0)$ \\
\hline Pre-Crisis & $-1.176^{b}$ & $-11.276^{b, *}$ & $\mathrm{I}(1)$ & $\begin{array}{l}2.702^{a, * * *} \\
- \\
2.582^{a, * * *}\end{array}$ & $\longrightarrow$ & $\mathrm{I}(0)$ \\
\hline Post-Crisis & $-1.476^{b}$ & $-7.216^{b, *}$ & $\mathrm{I}(1)$ & $-1.307^{b}$ & $-5.968^{b, *}$ & $\mathrm{I}(1)$ \\
\hline
\end{tabular}


Table 2b: Test of Stationarity Results with Structural breaks

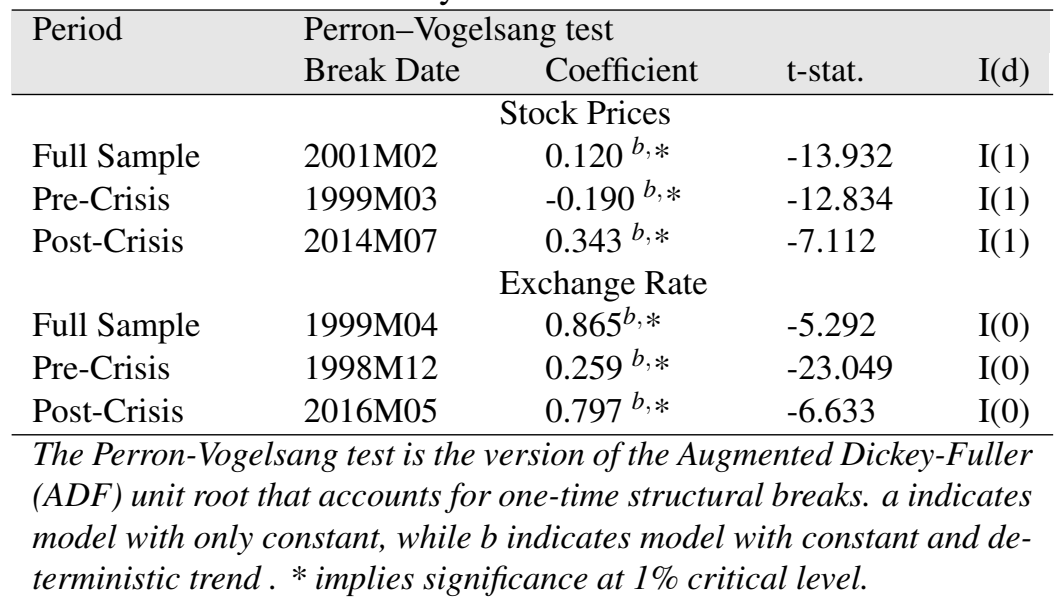

All the unit root tests results indicate that the stock prices are nonstationary, until first difference is taken (see Tables $2 \mathrm{a}$ and $2 \mathrm{~b}$ ). For exchange rate, the results are mixed across the unit root tests. While the DFGLS shows that exchange rate is first-difference stationary, PP test and structural breaks-based ADF test suggest level-stationarity in most cases. These mixed results substantiate the choice of Autoregressive Distributed Lag (ARDL) model of this study. It is worth pointing out that even if all the series are first difference-stationary, it imposes no restriction on the choice of the ARDL model. Pesaran et al. (2001) prove that the model can handle series that are all stationary at level or at first difference or have mixed integration orders.

\subsection{Estimation Results}

\subsubsection{Full Sample Estimation Results}

The discussion of the results is commenced with the symmetric model (see Table 3). There is clearly no refutation to the hypothesis of the Portfolio Balance Theory (PBT) that there is an inverse relationship between stock price and exchange rate, with the former serving as the predictor of the latter. Whether or not structural breaks are accounted for, it does not erode the postulation of the theory. In specific terms, stock price imposes significant negative impact on exchange rate in both short- and long-run, except that the effect is greater in the long-run. For instance, exchange rate negatively responds to a unit change in stock price by $0.063 \%$ and $0.071 \%$ in the short-run under the models without and with structural breaks respectively. The long run negative impacts, however, are $0.595 \%$ and $0.095 \%$ respectively when structural breaks are not accounted for and when they are. When nonlinearities are not 
Portfolio Balance Approach to Asymmetries, Structural Breaks and Financial Crisis: Testing a Model for Nigeria

Adekoya

put into consideration, it is evident from these results that the PBT does not only hold for Nigeria, it is stable regardless of structural shifts. This validation is corroborated by studies such as Dahir et al. (2016), Walid et al. (2011), Salisu and Ndako (2017), among others.

Table 3: Regression Results for Full Sample

\begin{tabular}{|c|c|c|c|c|}
\hline \multirow[t]{2}{*}{ Variable } & \multicolumn{2}{|c|}{ Symmetry } & \multicolumn{2}{|c|}{ Asymmetry } \\
\hline & Without Breaks & With Breaks & Without Breaks & With Breaks \\
\hline$p$ & $-0.595^{*}(0.105)$ & $-0.095^{*}(0.016)$ & $-\cdots--$ & $-\cdots--$ \\
\hline$\Delta p$ & $-0.063 *(0.012)$ & $-0.071 *(0.015)$ & ----- &.---- \\
\hline$p^{+}$ & $-\ldots$ & $-\ldots$ & $-0.525 * *(0.237)$ & $-0.478 *(0.125)$ \\
\hline$p^{-}$ & $-\ldots$ & $--_{-}-$ & $-1.439 *(0.525)$ & $-0.981 *(0.187)$ \\
\hline$\Delta p^{+}$ & $-\ldots$ & $-\ldots$ & $-0.826 *(0.024)$ & $\begin{array}{l}-0.834 * \\
(0.023)\end{array}$ \\
\hline$\Delta p^{-}$ & $-\ldots$ & $-\ldots$ & $-0.839 *(0.024)$ & $-0.847 *(0.024)$ \\
\hline B1 & $-\ldots$ & $0.421 *(0.140)$ & $-\ldots-\ldots$ & $1.139 *(0.208)$ \\
\hline$B 2$ & $--_{-}^{-}-$ & $-0.215(0.144)$ & $-\ldots$ & $-0.058(0.198)$ \\
\hline B3 & $-\ldots-\ldots$ & $-0.120(0.134)$ & $-\ldots$ & $0.615^{*}(0.196)$ \\
\hline$\Delta B 1$ & $-\ldots-\ldots$ & $0.073 * *(0.029)$ & $-\ldots$ & $0.041 *(0.012)$ \\
\hline$\Delta B 2$ & $-\ldots$ & $-0.037(0.026)$ & $-\ldots-$ & $-0.002(0.006)$ \\
\hline$\Delta B 3$ &.---- & $-0.021(0.024)$ & $-\ldots-$. & $0.022 *(0.007)$ \\
\hline$C$ & $7.002 *(0.501)$ & $6.420 *(0.309)$ & $9.044 *(1.781)$ & $7.339 *(0.681)$ \\
\hline Trend & $0.006 *(0.001)$ & $0.007 *(0.002)$ & $0.006 *(0.002)$ & $-\ldots$ \\
\hline$\Delta$ Trend & $0.001 *(0.000)$ & $0.001 *(0.000)$ & $0.001 * * *(0.000)$ & $-\cdots--$ \\
\hline ECT & $-0.105^{*}(0.019)$ & $-0.172 *(0.028)$ & $-0.019 * *(0.009)$ & $-0.036 *(0.013)$ \\
\hline F-stat Bounds & $6.287 * * *$ & 2.648 & $57.506 *$ & $32.323 *$ \\
\hline $\operatorname{Adj} R^{2}$ & 0.977 & 0.977 & 0.996 & 0.996 \\
\hline $\mathrm{LM}(2)$ & $0.265(0.767)$ & $\begin{array}{l}2.502 * * * \\
(0.084)\end{array}$ & $2.443 * * *(0.089)$ & $\begin{array}{l}1.460 \\
(0.234)\end{array}$ \\
\hline $\mathrm{LM}(4)$ & $0.490(0.743)$ & $2.867 * *(0.024)$ & $1.525(0.195)$ & $\begin{array}{l}1.120 \\
(0.348)\end{array}$ \\
\hline RESET & $2.351(0.127)$ & $\begin{array}{l}3.687 * * * \\
(0.056)\end{array}$ & $1.000(0.318)$ & $\begin{array}{l}0.118 \\
(0.731)\end{array}$ \\
\hline
\end{tabular}

$*, * *$, and $* * *$ indicate significance at 1\%, 5\% and 10\% respectively. Values in brackets are standard errors, while those in square brackets are probabilities. The inclusion of trend is subject to its significance at the maximum of $10 \%$ critical level.

Table 4: Bai-Perron (2003) Structural Break Dates

\begin{tabular}{|c|c|c|c|}
\hline Models & Breaks & Range & Signs \\
\hline \multirow[t]{4}{*}{ Symmetry } & 2000M10 & 1997M09- & - \\
\hline & 2007M10 & 2000M10- & + \\
\hline & 2013M03 & 2007M10- & - \\
\hline & & 2013M03- & - \\
\hline \multirow[t]{4}{*}{ Asymmetry } & 2000M10 & 1997M09- & $-/-$ \\
\hline & 2007M10 & 2000M10- & $+/+$ \\
\hline & 2013M03 & 2007M10- & $-/-$ \\
\hline & & 2013M03- & $-1-$ \\
\hline
\end{tabular}


Table 5: Joint Significance Test for Structural Breaks

\begin{tabular}{|c|c|c|}
\hline Model & $\begin{array}{l}\text { Presence of Structural } \\
\text { Breaks }\end{array}$ & Does it Matter? \\
\hline Symmetry & $\begin{array}{l}5.324 * \\
{[0.006]}\end{array}$ & $\sqrt{ }$ \\
\hline Asymmetry & $\begin{array}{l}7.283 * \\
{[0.001]}\end{array}$ & $\sqrt{ }$ \\
\hline
\end{tabular}

The error correction term which measures the speed of adjustment to long-run equilibrium is seen to observe the three standard properties required for all the models (i.e. the symmetric and asymmetric models when structural breaks are accounted for, and when they are not put into consideration) (see Table 3). First, they are significant; second, they are negative; and third, they are less than one in absolute terms. This long-run evidence is further corroborated by the F-statistic bounds when compared with the critical bounds values reported in Table A1. In essence, when asymmetries are not accounted for, the models without and with structural breaks show that the speed of adjustment to long-run equilibrium is $10.5 \%$ and $17.2 \%$ monthly. A reduction in the speed of adjustment is however observed when asymmetries are put into consideration as they become $1.9 \%$ and $3.6 \%$ for the models without and with structural breaks. Furthermore, the relevant diagnostic test results are reported in the lower panel of Table 3. The serial correlation is evaluated at lags 2 and 4 to ensure robustness. Except for the symmetric model with structural breaks where there is relative evidence of serial correlation particularly at the lag order of 4 , the null hypotheses of no serial correlation, and linearity of specified models cannot be rejected at the conventional 5\% significance level. The relative poor performance of the symmetric model with breaks is less perturbing since it has been confirmed through the Wald test whose results are reported in Table 6 that the role of asymmetries in the nexus between exchange rate and stock price cannot be jettisoned, thereby making the results of the asymmetric model to be more accurate and appreciated for relevant policy decisions.

Meanwhile, three structural break dates are identified by the Bai and Perron (2003) test. The breaks occurred respectively in October, 2000, October 2007 and March, 2013 (see Table 4), and they depict major world events. For instance, the break dates coincidentally relate to the 1999/2000 up-rise of the Middle-East, global financial crisis that began in the late 2007 
but took its heat in 2008, and the Arab Swings of 2013. The beauty of the Bai-Perron test is its ability to provide regression estimates for the respective break dates. Endogenously considered in the regression model, the need to account for the structural breaks is verified and confirmed in Table 5. The results show that considering structural breaks significantly reduce the magnitude of the effect of stock price on exchange rate, although the effect is still negative. Also, only the 1999/2000 up-rise of the Middle-East proves significant in driving exchange rate of Nigeria. The up-rise caused a significant disruption of crude oil, leading to increase in its global price. This further drives up the price of domestic non-tradable goods, and then exchange rate.

Can the results be altered by asymmetric changes in stock prices? We turn to the asymmetric analysis to validate or refute the PBT under this circumstance. In this case, the significance of the positive and negative stock price changes is first evaluated.

Table 6: Asymmetric Wald Test Results

\begin{tabular}{|c|c|c|c|c|c|}
\hline \multirow[t]{2}{*}{ Period } & \multicolumn{2}{|c|}{ Wald Statistic } & \multicolumn{2}{|c|}{ Evidence of Asymmetry } & \multirow{2}{*}{$\begin{array}{l}\text { Choice } \\
\text { of Model }\end{array}$} \\
\hline & Short run & Long run & Short run & Long run & \\
\hline $\begin{array}{l}\text { Full Sample } \\
\text { (No Breaks) }\end{array}$ & $\begin{array}{l}166.846 * \\
{[0.000]}\end{array}$ & $\begin{array}{l}4.936 * * \\
{[0.027]}\end{array}$ & $\sqrt{ }$ & $\sqrt{ }$ & NARDL \\
\hline $\begin{array}{l}\text { Full Sample } \\
\text { (With Breaks) }\end{array}$ & $\begin{array}{l}173.880 * \\
{[0.000]}\end{array}$ & $\begin{array}{l}14.144 * \\
{[0.000]}\end{array}$ & $\sqrt{ }$ & $\sqrt{ }$ & NARDL \\
\hline Pre-Crisis & $\begin{array}{l}3.318 * * \\
{[0.040]}\end{array}$ & $\begin{array}{l}2.390 * * * \\
{[0.096]}\end{array}$ & $\sqrt{ }$ & $\sqrt{ }$ & NARDL \\
\hline Post-Crisis & $\begin{array}{l}7.191 * * * \\
{[0.008]}\end{array}$ & $\begin{array}{l}0.098 \\
{[0.754]}\end{array}$ & $\sqrt{ }$ & $\times$ & $\begin{array}{l}\text { NARDL } \\
\text { /ARDL }\end{array}$ \\
\hline
\end{tabular}

The Wald test presented in Table 6 discloses strong significance, implying that positive and negative changes in stock price have different effects on exchange rate, and should be separately accounted for rather than the symmetric stock price. As is the case for the symmetric model, the same break dates are identified (see Table 4). Thus, for the two cases (with and without breaks), both positive and negative stock price changes are significant in both shortand long-run, and the effects are negative. In other words, the significant and negative coef- 
ficients are sustained, although differences in magnitude of effect are expectedly observed. Comparing the results of positive and negative changes in stock price, it is seen that the latter has greater effect on exchange rate than the former both in the short- and long-run. The theoretical assertion of Dieci and Westerhoff (2013) and some empirical reports, such as Salisu and Ndako (2017) seem to be in line with these findings. With respect to the impacts of structural breaks, both the Middle-East up-rise and Arab swings of 2013 impose positive impact, as caused by their disruption of oil supply which increased the global price of oil. Consequently, the price of domestic non-tradable goods increased, thereby resulting into a rise in exchange rate.

We prove again therefore that asymmetries in the Nigerian foreign exchange rate-stock markets nexus under the portfolio balance framework have no disruptive effect on the empirical performance. Nevertheless, the roles of both structural breaks and asymmetries should not be jettisoned as they are significant in altering the magnitude of effect even though the proposed direction of effect suggested by the portfolio balance theory is unaffected.

\subsubsection{Sub-sample Results}

This study also examines the pre- and post-2008 global financial crisis behaviour of the exchange rate-stock price nexus to determine the influencing role of the financial turmoil on the stability of the PBT in Nigeria.

The results are presented in Table (7). Definitely, the results show that the global financial crisis has greater impact on the exchange rate-stock price relationship. Taking evidence first from the symmetric model, the short-run negative impact of $0.854 \%$ before the crisis drops to as low as $0.001 \%$ in the post-crisis period. To further gauge the impact of the financial turmoil, stock price totally loses significance in the long-run. In other words, in the pre-crisis period, increase in stock price appreciates the Nigerian currency to the tune of $0.888 \%$, but this significance is not established after the crisis. 
Portfolio Balance Approach to Asymmetries, Structural Breaks and Financial Crisis: Testing a Model for Nigeria

Table 7: Regression Results (Pre- and Post-Global Financial Crisis)

\begin{tabular}{|c|c|c|c|c|}
\hline Variable & $\begin{array}{l}\text { Symmetry } \\
\text { Pre-Crisis }\end{array}$ & Post-Crisis & $\begin{array}{l}\text { Asymmetry } \\
\text { Pre-Crisis }\end{array}$ & Post-Crisis \\
\hline$\Delta r(-1)$ & $-\cdots---$ & $0.392 *(0.077)$ & - - - - - & $0.339 *(0.079)$ \\
\hline$p$ & $-0.888 *(0.112)$ & $-0.022(0.051)$ & ----- & - - - - - \\
\hline$\Delta p$ & $-0.854 *(0.030)$ & $\begin{array}{l}-0.001^{*} \\
(0.0002)\end{array}$ & - - - - - & - - - - - \\
\hline$p^{+}$ & ----- & $-\ldots$ & $\begin{array}{l}-0.791 * * \\
(0.364)\end{array}$ & $-1.953(1.542)$ \\
\hline$p^{-}$ & ----- & ----- & $\begin{array}{l}-0.755^{* *} \\
(0.349)\end{array}$ & $-3.312(8.692)$ \\
\hline$\Delta p^{+}$ & - - - - - & - - - - - & $\begin{array}{l}-0.047 * * \\
(0.018)\end{array}$ & $\begin{array}{l}-0.253 * \\
(0.048)\end{array}$ \\
\hline$\Delta p^{-}$ & ----- & ---- & $\begin{array}{l}-0.045^{* *} \\
(0.019)\end{array}$ & $\begin{array}{l}-0.255^{*} \\
(0.049)\end{array}$ \\
\hline$C$ & $7.535 *(0.476)$ & 8.740 (8.399) & $8.338 *(1.672)$ & $\begin{array}{l}18.762 \\
(34.531)\end{array}$ \\
\hline Trend & $0.021 *(0.002)$ & - - - - - & ----- & $-\cdots$ \\
\hline$\Delta$ Trend & $0.002 *(0.001)$ & - - - - - & $-\cdots--$ & ----- \\
\hline ECT & $-0.082 * *(0.035)$ & $-0.004(0.009)$ & $-0.059 *(0.021)$ & $-0.003(0.010)$ \\
\hline F-stat Bounds & 4.282 & 1.419 & 3.403 & 2.852 \\
\hline Adj $R^{2}$ & 0.994 & 0.994 & 0.954 & 0.994 \\
\hline LM2 & $4.022 * *(0.021)$ & $3.124 * *(0.048)$ & $0.024(0.976)$ & $1.674(0.192)$ \\
\hline LM (4) & $\begin{array}{l}2.087 * * * \\
(0.087)\end{array}$ & $1.643(0.168)$ & $0.093(0.985)$ & $0.984(0.419)$ \\
\hline RESET & $46.678 *(0.000)$ & $\begin{array}{l}3.148 * * * \\
(0.079)\end{array}$ & $0.719(0.398)$ & $1.877(0.173)$ \\
\hline
\end{tabular}

Considering asymmetries, the Wald test again indicates that they matter both in the shortand long-run for the pre-crisis period but only necessary in the short-run for the post-crisis period (see Table 6). The insignificance of the long-run Wald test of the asymmetries of the post-crisis period suggests that positive and negative stock price changes have no long-run effect on exchange rate. This confirms the significant impact of the crisis. Considering the asymmetric regression estimates in the pre-crisis period, a unit percentage increase in each of positive and negative stock price changes appreciate the naira in the short-run by $0.047 \%$ and $0.045 \%$ respectively. On the other hand, naira gains higher value by $0.791 \%$ and $0.755 \%$ respectively in the long-run. The effect seems greater for positive stock price change. For the post-crisis analysis, only short-run evidence is discovered with the negative impacts of positive and negative stock price changes being $-0.253 \%$ and $-0.255 \%$ respectively. 
Even though the F-statistic values of the Bounds test when compared with the critical bounds values in Table A2 suggest that the null hypothesis of the cointegration should be rejected for the four models in Table 7 (except the asymmetric model for the pre-crisis period where inconclusive evidence is found), they error correction terms for the symmetric and asymmetric models for the pre-crisis period fulfill the three conditions needed to infer long-run relationship. The coefficients are significant, negative, less than unity in absolute value. Therefore, we suitable conclude long-run evidence for the pre-crisis period even though the Bounds test suggests otherwise. This is unlike the symmetric and asymmetric models for the post-crisis period where both the error correction terms and Bounds test suggest lack of long-run relationship. Based on the coefficients of the error correction terms therefore, there will be an adjustment to long-run equilibrium at a speed of $8.2 \%$ and $5.9 \%$ (under symmetric and asymmetric models respectively) monthly in the pre-crisis period following a one-time shock in the short-run. We further reveal through the diagnostic tests presented in the lower panel of Table 7 that the results (especially for the asymmetric models) are reliable following the non-rejection of the null hypotheses of no serial correlation, and correct specification of the models. The few cases where there are exemptions are mainly associated with the symmetric models, but this again imposes no concern as the Wald test has indicated that asymmetries should be accounted for (see results in Table 6), thus making the asymmetric model to outperform the symmetric model.

Overall, the significance of stock price (symmetric and asymmetric) in the short-run and its insignificance in the long-run in the post-crisis period can be put to rational justification. Critically, the 2008 global financial crisis originated from the advanced countries, particularly the United States. The impact was not immediately felt as it took a while before the crisis spilled over to the financial and stock markets of most developing countries including Nigeria. This in mind, the crisis is not expected to immediately affect the exchange rate-stock price relationship, but its long-run impact is rightly expected since the spillover became evident after some time. These evidences are found to be supported by the graphical analysis in Figure 1. Hence, it is seen that the stability of the PBT, especially in the long-run, is subject to the occurrence of the financial crisis. In other words, the consistency of the PBT can be challenged in some countries following a major crisis, such as is established for Nigeria in this study. It is also not out of place to infer from the results that the foreign exchange market 
appears to be a good hedge against stock market risks. With the established negative relationship between them, a fall in stock prices is followed by increase in exchange rate. Hence, during the periods of falling stock prices which imply decrease in returns and consequently represent losses to investors, they can find cover in the foreign exchange market which offers high returns following the increase in exchange rate.

\section{Conclusion and Recommendations}

This study empirically analyzes the exchange rate-stock price nexus in Nigeria. Particularly, it tests the Portfolio Balance Theory (PBT) with asymmetries and structural breaks in the model, and assesses the stability of the theory in the face of the 2008 global financial crisis. This study concludes that the PBT holds for Nigeria with asymmetry and structural breaks, but the 2008 global financial crisis dampens the impact of stock price on exchange rate. Meanwhile, although the exchange rate-stock price relationship under the PBT framework is stable, the roles of asymmetries and structural breaks (which include important international events such as the 1999/2000 up-rise of the Middle-East, global financial crisis that began in the late 2007 but took its heat in 2008, and the Arab Swings of 2013) are important as they influence the magnitude of effect.

For policy recommendations, better stock market performance through better portfolio diversification and risk-hedging assets should be enhanced for better performance of the Nigerian currency. This requires that assets that tend to be relatively stable in the face of risks from various sources should be considered for trading on the Nigerian stock exchange. With this, the performance of the stock market is strengthened, and consequently the Nigerian currency which tends to be sensitive to the stock market behaviour. Also, the outcomes of this study have implications for agencies that are concerned with stabilization and forecast of the exchange rate. For instance, the monetary authority in Nigeria needs to understand that exchange rate responds asymmetrically to stock price, and so, must incorporate that in its exchange rate forecast. This is also true for other non-governmental agencies, including Bureau de Change. Lastly, Nigeria needs to be economically strengthened through the formulation of relevant policies that ensure economic stability. This will ensure that her economy is formidable to the adverse impact of various external shocks and crisis. This is because this study has shown that the prediction of the PBT may not be valid after the break out of any financial crisis that strongly affects the economy. 


\section{References}

Abraham, T. F. (2016). Exchange rate policy and falling crude oil prices: Effect on the Nigerian stock market. CBN Journal of Applied Statistics 7, 111-123.

Adaramola, A. O. (2012). Exchange rate volatility and stock market behaviour: The Nigerian experience. European Journal of Business and Management 4(5), 31-39.

Adjasi, C., Biekpe, N. B. \& Osei, K. A. (2011). Stock prices and exchange rate dynamics in selected African countries: A bivariate analysis. African Journal of Economic and Management Studies 2(2), 143-164.

Aggarwal, R. (1981). Exchange rates and stock prices: A study of the US capital markets under floating rates. Akron Business and Economic Review 12, 7-12.

Alimi, A. S. \& Adediran, I. A. (2018). The nexus between stock market prices and external shocks: Evidence from nonlinear ARDL on selected firms in the Nigerian stock market. Global Journal of Management and Business Research 18, 54-59.

Aliyu, U. R. (2009). Stock prices and exchange rate interactions in Nigeria: An intra-global financial crisis maiden investigation. MPRA Paper, 13283.

Aydemir, O. \& Demirhan, E. (2009). The relationship between stock prices and exchange rates: Evidence from Turkey. International Research Journal of Finance and Economics 23, 207-216.

Bai, J. \& Perron, P. (2003).Computation and analysis of multiple structural change models. Journal of Applied Econometrics 18(1), 1-22.

Benjamin, O. O. \& Fatile, J. O. (2019). Structural analysis of the effect of exchange rate movement on stock market performance in Nigeria. MPRA Paper No. 98337. https://mpra.ub.uni-muenchen.de/98337.

Branson, W. H. (1983). Macroeconomic determinants of real exchange risk. In: Herring, R. J. (Ed.), Managing Foreign Exchange Risk. Cambridge University Press, Cambridge, United Kingdom.

Chkili, W. \& Nguyen, D. K. (2014). Exchange rate movements and stock market returns in a regime-switching environment: Evidence from BRICS countries. Research in International Business and Finance 31, 46-56.

Dahir, A. M., Mahat, F., Razak, N. H. \& Bany-Ariffin, A. N. (2017).Revisiting the dynamic relationship between exchange rates and stock prices in BRICS countries: A wavelet analysis. Borsa Istanbul Review 18(2), 101-113. 
Diamandis, P. F. \& Drakos, A. A. (2011). Financial liberalization, exchange rates and stock prices: Exogenous shocks in four Latin American countries. Journal of Policy Modeling 33, 381-394.

Dieci, R. \& Westerhoff, F. (2013). On the inherent instability of international financial markets: Natural nonlinear interactions between stock and foreign exchange markets. Applied Mathematics and Computation 221, 306-328.

Dornbusch, R. \& Fischer, S. (1980). Exchange rates and the current account. American Economic Review 70, 960-971.

Effiong, E. L. (2016). Nonlinear dependence between stock prices and exchange rate in Nigeria. MPRA Paper No. 74336.

Fasanya, I. O., Odudu, T. F. \& Adekoya, O. B. (2018). Oil and agricultural commodity prices in Nigeria: New evidence from asymmetry and structural breaks. International Journal of Energy Sector Management 13,377-401.

Frankel, J. A. (1983). Monetary and portfolio-balance models of exchange rate determination. In: Bhandari, J. S., Putnam, B. H. (Eds.), Economic Interdependence and Flexible Exchange Rates. MIT Press, Cambridge, 84-115.

Gavin, M. (1989). The stock market and exchange rate dynamics. Journal of International Money and Finance 8(2), 181-200.

Khan, A. \& Abbas, Z. (2015). Portfolio Balance Approach: An empirical testing. Journal of Economics and International Finance 7, 137-143.

Kutty, G. (2010). The relationship between exchange rates and stock prices: The case of Mexico. North American Journal of Finance and Banking 4(4), 1-12.

Lawal, M. \& Ijirshar, V. U. (2015).Empirical analysis of exchange rate volatility and Nigerian stock market performance. International Journal of Scientific Research 4(5), 1592-1600.

Leung, H., Schiereck, D. \& Schroeder, F. (2017). Volatility spillovers and determinants of contagion: Exchange rate and equity markets during crises. Economic Modelling 61, 169-180.

Lin, C. (2012). The comovement between exchange rates and stock prices in the Asian emerging markets. International Review of Economics and Finance 22, 161-172.

Lintner, J. (1965). The valuation of risk assets and the selection of risky investments in stock portfolios and capital budgets. Review of Economics and Statistics 47, 13-37.

Mitra, R. (2017). Stock market and foreign exchange market integration in South Africa. World Development Perspectives 6, 32-34. 
Moore, T, \& Wang, P. (2014). Dynamic linkage between real exchange rates and stock prices: Evidence from developed and emerging Asian markets. International Review of Economics and Finance 29, 1-11.

Okpara, G. C. \& Odionye, J. C. (2012). Analysis of the relationship between exchange rate and stock prices: Evidence from Nigeria. International Journal of Current Research 4 (3), 175-183.

Omokehinde, J. O., Abata, M. A. \& Migiro, S. O. (2017).Foreign exchange news announcements and the volatility of stock returns in Nigeria. SPOUDAI-Journal of Economics and Business 67 (3), 2-17.

Osamwonyi, I. O. \& Evbayiro-Osagie, E. I. (2012).The relationship between macroeconomic variables and stock market index in Nigeria. Journal of Economics 3 (1), 55-63.

Pan, M., Fok, R. C. \& Liu, Y. A. (2007). Dynamic linkages between exchange rates and stock prices: Evidence from East Asian markets. International Review of Economics and Finance 16, 503-520.

Ross, S. A. (1976). The arbitrage theory of capital asset pricing. Journal of economic theory 13 (3), 341-360.

Salisu, A. A. \& Fasanya, I. O. (2013).Modelling oil price volatility with structural breaks. Energy Policy 52, 554-562.

Salisu, A. A. \& Ndako, U. B. (2017). Modelling stock price-exchange rate nexus in OECD countries: A new perspective. Centre for Econometric and Allied Research, University of Ibadan Working Papers Series, WPS 0038.

Sharpe, W. F. (1964). Capital asset prices: A theory of market equilibrium under conditions of risk. Journal of Finance 19 (3), 425-442.

Shin, Y., Yu, B. \& Greenwood-Nimmo, M. (2014). Modelling asymmetric cointegration and dynamic multipliers in an ARDL framework. In Festschrift in Honor of Peter Schmidt, Springer New York, 281-314.

Sui, L. \& Sun, L. (2015). Spillover effects between exchange rates and stock prices: Evidence from BRICS around the recent global financial crisis. Research in International Business and Finance 36, 459-471.

Walid, C., Chaker, A., Masood, O. \& Fry, J. (2011).Stock market volatility and exchange rates in emerging countries: A Markov-state switching approach. Emerging Markets Review 12, 272-292.

Zivkov, D., Njegic, J. \& Mirovic, V. (2016).Dynamic nexus between exchange rate and stock prices in the major East European economies. Prague Economic Papers 25 (6), 686-705. 
Portfolio Balance Approach to Asymmetries, Structural Breaks and Financial Crisis: Testing a Model for Nigeria

Adekoya

Zubair, A. (2013). Causal relationship between stock market index and exchange rate: Evidence from Nigeria. CBN Journal of Applied Statistics 4, 87-110.

\section{Appendix}

Table 1A: Critical Bounds Values for Full Sample

\begin{tabular}{lllllllll}
\hline & \multicolumn{3}{c}{ Symmetry } & \multicolumn{3}{c}{ Asymmetry } \\
& \multicolumn{2}{l}{ Without Breaks } & \multicolumn{2}{c}{ With Breaks } & \multicolumn{2}{c}{ Without Breaks } & \multicolumn{2}{c}{ With Breaks } \\
\hline & $\mathrm{I}(0)$ & $\mathrm{I}(1)$ & $\mathrm{I}(0)$ & $\mathrm{I}(1)$ & $\mathrm{I}(0)$ & $\mathrm{I}(1)$ & $\mathrm{I}(0)$ & $\mathrm{I}(1)$ \\
$1 \%$ & 8.74 & 9.63 & 4.40 & 5.72 & 6.34 & 7.52 & 3.41 & 4.68 \\
$2.5 \%$ & 7.46 & 8.27 & 3.89 & 5.07 & 5.79 & 6.59 & 2.96 & 4.18 \\
$5 \%$ & 6.56 & 7.30 & 3.47 & 4.57 & 4.87 & 5.85 & 2.62 & 3.79 \\
$10 \%$ & 5.59 & 6.26 & 3.03 & 4.06 & 4.19 & 5.06 & 2.26 & 3.35 \\
\hline
\end{tabular}

Table A2: Critical Bounds Values for Sub-samples

\begin{tabular}{lllllllll}
\hline & \multicolumn{3}{c}{ Symmetry } & \multicolumn{3}{c}{ Asymmetry } \\
& Pre-crisis & \multicolumn{3}{c}{ Post-crisis } & \multicolumn{3}{c}{ Pre-crisis } & Post-crisis \\
\hline & $\mathrm{I}(0)$ & $\mathrm{I}(1)$ & $\mathrm{I}(0)$ & $\mathrm{I}(1)$ & $\mathrm{I}(0)$ & $\mathrm{I}(1)$ & $\mathrm{I}(0)$ & $\mathrm{I}(1)$ \\
$1 \%$ & 8.74 & 9.63 & 6.84 & 7.84 & 5.15 & 6.36 & 5.15 & 6.36 \\
$2.5 \%$ & 7.46 & 8.27 & 5.77 & 6.68 & 4.41 & 5.52 & 3.79 & 5.52 \\
$5 \%$ & 6.56 & 7.30 & 4.94 & 5.73 & 3.79 & 4.85 & 4.41 & 4.85 \\
$10 \%$ & 5.59 & 6.26 & 4.04 & 4.78 & 3.17 & 4.14 & 5.15 & 4.14 \\
\hline
\end{tabular}

